Article

\title{
Virtualization of Higher Education during COVID-19: A Successful Case Study in Palestine
}

\author{
Saida Affouneh ${ }^{1, *}$, Zuheir N. Khlaif ${ }^{1}\left[\right.$, Daniel Burgos ${ }^{1,2, *}$ and Soheil Salha ${ }^{1}$ \\ 1 Faculty of Educational Sciences and Teachers' Training, An Najah National University, \\ Nablus 44830, Palestine; zkhlaif@najah.edu (Z.N.K.); ssalha@najah.edu (S.S.) \\ 2 Research Institute for Innovation \& Technology in Education (UNIR iTED), Universidad Internacional de La \\ Rioja (UNIR), 26006 La Rioja, Spain \\ * Correspondence: s.affouneh@najah.edu (S.A.); daniel.burgos@unir.net (D.B.)
}

Citation: Affouneh, S.; Khlaif, Z.N.; Burgos, D.; Salha, S. Virtualization of Higher Education during COVID-19: A Successful Case Study in Palestine. Sustainability 2021, 13, 6583. https:// doi.org/10.3390/su13126583

Academic Editor: Dina Zoe Belluigi

Received: 9 January 2021

Accepted: 1 June 2021

Published: 9 June 2021

Publisher's Note: MDPI stays neutral with regard to jurisdictional claims in published maps and institutional affiliations.

Copyright: (c) 2021 by the authors. Licensee MDPI, Basel, Switzerland. This article is an open access article distributed under the terms and conditions of the Creative Commons Attribution (CC BY) license (https:// creativecommons.org/licenses/by/ $4.0 /)$.

\begin{abstract}
The purpose of the study is to explore students' and faculty members' responses to universities' migration from face-to-face to online instruction as a result of the coronavirus (COVID19) crisis. To this extent, a qualitative approach was used for data collection and involved a number of qualitative methods: an open-ended question survey, focus group discussion, social media data, and university reports. Additionally, a thematic analysis was used for data analysis. The findings of the study reveal that students and faculty members were overwhelmed and stressed at the beginning, but as they started to acclimate to it, faculty members were satisfied. However, students seemed to be dissatisfied with this new approach to learning. Furthermore, faculty members and students both mentioned different challenges they had faced. The study reports on the technological tools used to mitigate the emerging challenges of both students and faculty members. Evaluating and assessing students was a main challenge for faculty members as the study analyzes the assessment and evaluation tools that they use in their online teaching. Comparative studies from Palestine and other countries are suggested for future research.
\end{abstract}

Keywords: coronavirus; COVID-19; distance education; higher education; online learning

\section{Introduction}

\subsection{Education and Crises}

Education is a human right even in a crisis situation. The right to education involves different requirements for various levels of education [1]. International reports have demonstrated that education has an important role in improving health, livelihood, and peacemaking in different contexts. The new Sustainable Development Goals (2015-2030) also include a focus on "inclusive and equitable quality education and [to] promote lifelong learning opportunities for all" (p. 4). Crisis and conflict present significant obstacles to reaching these global education goals. In any country, public emergency management is a major task of public administration in the face of emergencies in the country, including the outbreak of diseases, natural disasters, and wars [2]. The coronavirus (hereafter, COVID-19) started in late 2019 in Wuhan, China, and the outbreak rapidly spread worldwide [3]. Many countries in the worldwide state of emergency responded to the outbreak of COVID-19 by implementing important decisions on the ground, including social distancing, curfews, lockdown of cities, and closing of schools and universities [3,4]. Part of the emergency plans entailed closing schools and universities but without a halt to learning, given the uncertainty of when the crisis would end [5].

Crises and conflicts are among the biggest obstacles to ensuring inclusive and equitable quality education at all levels [6]. Supporting and fostering education in public and higher education during a crisis using information and communication technology (hereafter, ICT) has gained increasing attention in recent years [7]. ICT has the capacity to enhance, support, and enable education for the most marginalized, as well as those affected by war, natural 
disasters, and the rapid spread of disease [8,9]. In different contexts, many ICT tools such as the Internet, radio, smart phones, TV channels, tablets, laptops, and computers can facilitate teaching and learning in several ways such as e-learning, online education, and distance education $[10,11]$.

UNESCO has established the Global COVID-19 Coalition, which brings together the private sector with partners from local communities to help counties deploy remote education to schools and universities in order to mitigate educational disruptions and maintain social contact with learners [12]. According to the UNESCO Institute of Statistics, more than $80 \%$ of students are out of their educational institutions due to COVID-19. The world economic forum reported that the COVID-19 pandemic is critically affecting global education, and unexpected consequences may handicap the education process.

\subsection{COVID-19 and Palestine}

Palestine, located in the heart of Middle East, is an unstable country with a shortage of natural resources. It is also under Israeli occupation. These factors have negatively influenced the educational system [13]. In the Palestinian territories, COVID-19 was discovered in the second half of February 2020. Subsequently, the Palestinian Authority declared a state of emergency in the Palestinian territories to mitigate the outbreak. Instruction in both higher and public education has been impacted by the emergency. All schools and higher education institutions were affected by the initial closure for 30 days. Innovative solutions emerged to ensure that disruption to education was minimized and institutions could cope over the situation. Therefore, higher education institutions responded immediately to the universities' closure with a transition to distance education and exploitation of the e-learning centers in these institutions to provide distance learning. An-Najah National University, the setting of the case study in this research, responded through the activation of distance education and formed a crisis committee to put an emergency plan in place to start distance education; several scenarios were created and developed through the closure days.

\subsection{What Universities Closure Means in Palestine}

Higher education institutions in Palestine closed without stopping teaching and learning. The staff members work from home to provide students with the essential teaching and learning that is required to survive the academic year $[13,14]$. This procedure aims to fight the outbreak of the epidemic by suspending teaching on campuses and shifting teaching and learning into distance education through the activation of the elearning paradigm [15]. The Palestinian prime minister stated, "Schools and universities should transform education into distance education" [14].

All the Palestinian universities have started the transformation to distance education based on the decision of the Ministry of Higher Education in Palestine. However, the procedures and actions in each university are different based on its infrastructure and faculty readiness to move to online. All of the universities put instructions to move to online learning, but the details about how these instructions may be implemented and how each institute should initiate it depend on the readiness of the students, the staff, and the infrastructure. Despite the fact that Palestinian universities have suffered from long years of closure and interruption due to occupation, many universities were not ready to move online due to shortage of financial situation and poor technological infrastructure [8].

Given the current circumstances, a debate has arisen on social media platforms and in the media about whether distance education can adequately replace traditional education, whether faculty members and students may experience work overload, or whether the home is a desirable learning environment [16]. The availability of infrastructure and internet access at staff members' and students' homes, the methodology used to evaluate students in an online environment, the readiness and experience of faculty members to teach online, and the quality of the material content needed to achieve equitable and accessible education for all students are also questionable. 
Each university has tried to answer these questions based on its own infrastructure and its faculty members' readiness to teach online. Most universities have been flexible in allowing faculty members to use a wide range of content, tools, and applications to communicate with their students to support their growth, including using LMS such as Moodle, Google Classroom, and livestreaming applications such as the Zoom platform, in addition to other social media apps such as WhatsApp and Facebook [15].

\subsection{What the Closure of An-Najah in Palestine Means}

An-Najah National University is one of the universities that announced the transformation from traditional teaching into distance learning though the LMS of the e-learning center at the university. Students were unprepared for such a transition, as were many students in the world, since the situation was unclear. They did not know what to expect, how education would be delivered, or how they would be evaluated.

In consequence, the current research explores students' and faculty members' responses to the university transformation to online learning to reduce the spread of COVID19. The study did not evaluate the experiences of professors and students with distance education in COVID-19 crisis. As a description of what they are facing, it suggests future research in the field through analysis of students' comments and feedback on social media, as well as faculty members' attitudes and practices regarding distance education. Accordingly, the research questions explored in this study were:

1. How has ANNU responded to the universities' closure due to the outbreak of COVID-19?

2. What types of emerging technologies have been used in responding to the COVID-19 outbreak at ANNU?

3. How did students respond to distance education at ANNU in Palestine during the COVID-19 crisis?

4. What are the challenges of distance education at ANNU from faculty members' and students' perspectives?

\section{Literature Review}

Previous studies have explored how students and faculty members in higher education institutions responded to the emergency remote teaching and learning. For example, a qualitative study from United Arab Emirates investigated undergraduate students experience with emergency remote learning during COVID-19 [16]. Furthermore, Jeffery and Baur [17] conducted a stud to understand how undergraduate student learning environment changed and how students responded to the transition to online learning during crisis. Their study revealed that the classes change little from the traditional lectures, while laboratories changed dramatically in terms of decision-rich environment to passive observation [17].

A recent study conducted by Toquero [18] recommended higher education institutions to produce research to document and proliferate the responses of these institutions to the new learning environment during the pandemic. Moreover, qualitative and quantitative approach was used to study the perceptions of faculty members and students on online learning-teaching modes, which revealed that a clear vision for transition to online learning during crisis has a positive impact on adapting online learning from both students and faculty members. In addition, the administration focused on providing the essentialities and using existed resources to succeed in the transition process during the COVID-19 crisis [19].

A case study from Peking University reported five high-impact principals for online learning during crisis including effective delivery of online learning content, high relevance between student needs and instructional design, adequate instructional and technical support for students, high quality of student's engagement, and a clear plan to deal with unexpected technical issues with online learning platforms [20]. 


\subsection{Distance Education}

The distance education concept is related to teaching and learning that is typically conducted at a place remote from learners, requiring communication via technologies as well as special institutional organization [13]. Compared with traditional face-to-face education, distance education has its own unique features. Distance learning is usually used by adults with prior experience with it. Using distance education in educational institutions refers to the techniques of learning which are used to create, develop, and enrich electronic educational content delivered via ICT tools and applications [21]. Distance education identified as a combination of multiple forms of education with the use of new information technology [22]. Distance education facilitates interaction, shared experiences, and development of knowledge in many places, and it enables communication between a large number of learners at different sites within a state or in several states [23].

Distance education in higher education has become an increasingly common alternative to the traditional presentation of the course material by instructors [24]. Driven by the demands of the digital age where almost everything is done in a virtual environment, online courses are attractive options in higher education [25].

Distance education can address a variety of institutional needs [26]. These include space constraints, enrollment expansion within an existing physical campus infrastructure, revenue generation, access for diverse student populations, international outreach, and global competitiveness [27]. Aldiab et al. [28] stated that distance education requires responsibility for ensuring stability and sufficient infrastructure to support productive learning and to guarantee accessibility and equity for all teachers and learners.

For the purpose of our study, online learning during crisis refers to a kind of learning and teaching environment where (1) the learner is at a distance from the instructor due to the lockdown; (2) the instructor and learner are using some form of technology to access the learning resources; (3) the learning process occurs synchronously, asynchronously, or both; (4) the learner uses technology to interact with the instructor and with other learners; and (5) technical and instructional of support is provided to faculty members and learners.

\subsection{Coronavirus Impact}

The COVID-19 outbreak had affected 213 countries and territories around the world as of 9 July 2020 [3]. On July 08 , the WHO confirmed that the number of cases exceeded $12,170,845$ worldwide and that deaths were over 552,129 . Governmental agencies prepared for the worst amid the enormous impacts of COVID-19 on all aspects of daily life and human activities [29]. As governments have naturally focused on health services, education has suffered a huge blow as universities and schools scramble to provide rich learning experiences to students [30].

During this crisis, most universities throughout the world have changed their systems to online education or distance education. Some of them have switched to fully online courses and exams. Other universities already had a large number of their students in distance learning. In Palestine, COVID-19 generated an educational crisis and forced higher education institutions to urgently look for satisfactory solutions in order to sustain the educational process and provide real learning for students. It was a necessity to transition to a distance education approach to overcome the COVID-19 crisis. However, COVID-19 forced higher education institution to reorganize teaching in entrepreneurship education through using technological tools that support the development of entrepreneurship mindset for both students and faculty members through redesigning traditional learning to effectively address emergencies [24].

The world economic forum reported that the COVID-19 pandemic is critically affecting global education, and unexpected consequences may handicap the education process. During this crisis, most universities throughout the world have changed their systems to online education or distance education [31]. Some of them have switched to fully online courses and exams. Other universities already had a large number of their students in distance learning. In Palestine, COVID-19 generated an educational crisis and forced higher 
education institutions to urgently look for satisfactory solutions in order to sustain the educational process and provide real learning for students. It was a necessity to transition to a distance education approach to overcome the COVID-19 crisis [5]. Designing of learning activities based on the learner's characteristics, combination of the three types of presence (cognitive, social, and facilitatory), and the need to use suitable assessment of learning are crucial points in the remote learning environment during crisis [31].

\subsection{The Complexities of Education in Emergency Situations}

Emergencies occur in different contexts due to health epidemics, political conflicts, economic fallout, and natural disasters, and all can have a direct negative influence on education by preventing children from attending schools and young adults from going to their universities. The Palestinian educational system has been influenced many times by violence and unstable situations through school and universities closures in the last 10 years $[9,31]$.

A recent study by Khlaif and Salha [5] revealed various unanticipated challenges in education during COVID-19 in developing countries (such as broadening of digital inequity) that negatively impact students' engagement in the online learning environment.

A crisis in an educational institution is considered to be a traumatic event for the institution. It may happen inside or outside it, and it is framed by uncertainty, complexity, and urgency [32]. Zhao [33] determined that a flexible governmental system and a digital transformation of community were the most important features of education under crisis.

Rhema and Miliszewska [34] believed that distance education plays a significant role in teaching and learning in higher education during crises such as political upheavals and natural or man-made disasters. Pergel and Psychogios [35] discussed learning during crises and found that needs change in all aspects of policy, behavior, practices, institutional framework of learning, and individual methods of learning and cognition. Popovici and Mironov [36] admitted that using distance education in educational systems changes learning and teaching. Deverell and Olsson [37] found that distance education presents flexibility in learning during crisis conditions.

\subsection{How Learners Assessed Distance Education}

Evaluation of distance education has been the core of many studies. Khlaif et al. [38] found that students preferred blended learning to distance learning, while Messaoudi et al. [39] pointed to a high level of distance education preference among university students. Caliskan et al. [40] showed that distance education content is adaptable and reusable by students, but it is hard to assess its effectiveness. Li and Wang [41] showed the satisfaction of undergraduate students in distance education courses. Rudd et al. [42] supported the efficiency of distance education versus face-to-face learning as both graduates had the same opportunity in finding jobs. Jowsey et al. [43] revealed the effectiveness of distance courses in training, enriching experiences, and minimizing costs compared to the traditional approach. Jowsey et al. [43] also linked the efficiency of distance education with purposeful delivery, support, and flexible management. Sturmer et al. [44] correlated the success of distance education with friendly procedures and social integration which motivates learners to attend and participate. The findings of a study conducted by Rapanta et al. [20] expressed that the design of learning activities with certain characteristics, the combination of three types of presence (social, cognitive, and facilitatory) and the need for adapting assessment to the new learning requirements.

\section{Methods}

A qualitative approach was used to achieve the purpose of the study. The researchers used four tools for data collection including open-ended question form, online focus group sessions, students' comments on the university Facebook page, and official documents issued from the university. The mentioned tools in data collection enable us to explore the learning experiences of different stakeholders with a new phenomenon [45]. For this study, 
the phenomenon was the sudden transformation of the teaching and learning paradigm from traditional to distance education due to the outbreak of COVID-19.

The procedures to conduct the study are: In he first stage, we took to conduct the study was designing and developing the study tools based on the study questions and related studies. The developed tools were sent to five experts in the field of educational technology and education from different universities in Palestine to validate the accuracy of questions. We got a permission from the university to collect data from the faculty members for scientific research purposes. In addition, a consent form was developed to obtain participants' agreement to participate in the study, and another consent form was developed for audio recording of the focus group sessions. Since students' comments are public, we did not request the students' permission to use the data. However, we followed the ethics of research by not using the students' Facebook names.

In the second stage, we submitted an online open-ended question form on the university website with an invitation letter clarifying the purpose of the study and why we choose them to participate in the study. After analyzing the data received from the openended questions, we developed the focus group prompts based on the findings of the open-ended questions form. We invited the faculty members to participate in online focus group sessions.

In the third stage, we collected official documents including announcement and instruction about the transition to online learning during the pandemic crisis issued from the university administration and prepare these documents for analysis. Finally, we conducted a scanning of students comments and feedback on the video posted on the official page of the university on social media to find out the students' attitudes toward the transition to online learning during crisis.

\subsection{Context of the Study}

The study was conducted at An-Najah National University (ANNU), a large university located in northern Palestine. More than 19,000 students are enrolled in different schools at the university, and there are more than 150 undergraduate, master, and doctoral programs. The university established an e-learning center in 2012. The main responsibilities of the center are training faculty members to use technology in their courses, designing blended courses, and managing the learning management system at the university. From the first announcement of a state of closure in Palestine, ANNU started developing an emergency plan to implement distance education. The first step was conducting a meeting with faculty members who are experts in the e-learning paradigm and the staff of the eLearning center to check the readiness and requirements for the transformation and to identify the best technological tools to be used in online classes. The plan was designed initially to contain different scenarios depending on different presumptions. The next step was to present the suggested plan to the risk management committee to be adapted and discussed. Finally, an official message was delivered to all the staff to start implementing the distance/online learning. The schedule of online classes was the same as in the traditional classes with a few modifications as needed.

\subsection{Data Collection Procedures}

An open-ended questions form was the main data source for data collection from the participants in the current study. Thorndike and Thorndike-Christ [46] defined open-ended questions as a methodology to ask participants to write their own responses using their own words. Open-ended questions are used to explore attitudes and to gather information without limiting responses and omitting important information [46-48]. Therefore, the researchers developed an open-ended questionnaire in Arabic to investigate faculty members' responses to the transition from traditional education to distance education. The survey comprised four dimensions including demographic information about professors, types of technology used in distance education, challenges of distance education under the COVID-19 crisis, and recommendations. The researchers developed the dimensions of 
the research based on the research questions. In addition, the items for technology types were developed based on the university reports and technology available in the eLearning center at the university. The research granted the faculty members a chance to write about the challenges they faced and to reflect on their own practices. In addition, the participants were asked to write their recommendations to develop the distance education paradigm under COVID-19. Five experts, who each have publications in education and educational technology, revised the form in terms of clarity, simplicity, and word accuracy.

Focus group discussion was another source of data. The researchers developed the focus group discussion protocol and the prompts based on the findings of open-ended questions analysis. The criteria used to choose the participants of the study was: first, to have a previous experience with distance education prior to the COVID-19 crisis; second, to have started implementing distance learning; and finally, to be willing to share his/her experience with others. The participants of the focus group sessions consisted of 17 faculty members. The focus group was conducted over Zoom for two hours with one break of $15 \mathrm{~min}$.

Document analysis was used to analyze the reports and announcements issued by the university which were used as guidelines for the transformation process. Bowen [49] defined document analysis as a procedure for reviewing and evaluating to develop practical knowledge and gain understanding of printed and electronic material. Therefore, researchers used different official documents issued by the university to gain understanding of the university policy toward distance education in COVID-19.

Finally, students' comments on the official university social media page were analyzed to get a clear perspective about student attitudes toward distance education since students play an important role in distance education. All the researchers agreed to follow up with the students' comments on two announcements posted on the university page on social media. The researchers chose these two posts because they reflect the transition to online education. The first post was a video on the decision to transition into online education. The second post was about encouraging students to attend online courses. There were 750 comments on this post and 1000 comments on other posts. Therefore, the total number of student comments analyzed was 1750 .

\subsection{Participants}

A total of 610 out of 1200 faculty members responded to the open-ended questions form within two weeks. Table 1 represents the demographic information about the faulty members who participated in the survey.

Table 1. Participants characteristics according to gender and college.

\begin{tabular}{|c|c|c|c|c|c|c|}
\hline \multirow{3}{*}{ College } & \multicolumn{4}{|c|}{ Gender } & \multirow{2}{*}{\multicolumn{2}{|c|}{ Total }} \\
\hline & \multicolumn{2}{|c|}{ Male } & \multicolumn{2}{|c|}{ Female } & & \\
\hline & $\mathbf{N}$ & $\%$ & $\mathbf{N}$ & $\%$ & $\mathbf{N}$ & $\%$ \\
\hline Agriculture and Veterinary Medicine & 19 & $3.1 \%$ & 12 & $2.0 \%$ & 31 & $5.1 \%$ \\
\hline Economics and Social Studies & 73 & $12.0 \%$ & 25 & $4.1 \%$ & 98 & $16.1 \%$ \\
\hline Educational Sciences and Teachers' Training & 24 & $4.0 \%$ & 27 & $4.4 \%$ & 51 & $8.4 \%$ \\
\hline Engineering and Information Technology & 71 & $11.6 \%$ & 38 & $6.3 \%$ & 109 & $17.9 \%$ \\
\hline Fine Arts & 22 & $3.6 \%$ & 25 & $4.1 \%$ & 47 & $7.7 \%$ \\
\hline Humanities & 23 & $3.8 \%$ & 13 & $2.1 \%$ & 36 & $5.9 \%$ \\
\hline Islamic Law & 21 & $3.4 \%$ & 14 & $2.3 \%$ & 35 & $5.7 \%$ \\
\hline Law & 7 & $1.1 \%$ & 3 & $0.5 \%$ & 10 & $1.6 \%$ \\
\hline Medicine and Health Sciences & 75 & $12.3 \%$ & 57 & $9.3 \%$ & 132 & $21.6 \%$ \\
\hline Science & 40 & $6.6 \%$ & 21 & $3.4 \%$ & 61 & $10.0 \%$ \\
\hline Total & 375 & $61.5 \%$ & 223 & $38.5 \%$ & 610 & $100.0 \%$ \\
\hline
\end{tabular}

A focus group involving 17 professors from different schools was conducted online via Zoom for two hours with the professors' consent to record the session. The discussion 
concerned their experiences with distance education during COVID-19. We generated the prompts from faculty members' responses and the research questions of the study. There were five official documents issued by the university administration and eLearning center as a response to the lockdown. Table 2 represents the demographic information about the participants in the focus group session.

Table 2. Demographic information about the participants in the focus group sessions.

\begin{tabular}{|c|c|c|c|c|c|c|}
\hline \multirow{3}{*}{ College } & \multicolumn{4}{|c|}{ Gender } & \multirow{2}{*}{\multicolumn{2}{|c|}{ Total }} \\
\hline & \multicolumn{2}{|c|}{ Male } & \multicolumn{2}{|c|}{ Female } & & \\
\hline & $\mathbf{N}$ & $\%$ & $\mathbf{N}$ & $\%$ & $\mathbf{N}$ & $\%$ \\
\hline Agriculture and Veterinary Medicine & 1 & $5.9 \%$ & 1 & $5.9 \%$ & 2 & $11.8 \%$ \\
\hline Economics and Social Studies & 1 & $5.9 \%$ & 1 & $5.9 \%$ & 2 & $11.8 \%$ \\
\hline Educational Sciences and Teachers' Training & 1 & $5.9 \%$ & 1 & $5.9 \%$ & 2 & $11.8 \%$ \\
\hline Engineering and Information Technology & 1 & $5.9 \%$ & 1 & $5.9 \%$ & 2 & $11.8 \%$ \\
\hline Fine Arts & 1 & $5.9 \%$ & 1 & $5.9 \%$ & 2 & $11.8 \%$ \\
\hline Humanities & 0 & $0.0 \%$ & 1 & $5.9 \%$ & 1 & $5.9 \%$ \\
\hline Islamic Law & 1 & $5.9 \%$ & 0 & $0.0 \%$ & 1 & $5.9 \%$ \\
\hline Law & 1 & $5.9 \%$ & 0 & $0.0 \%$ & 1 & $5.9 \%$ \\
\hline Medicine and Health Sciences & 1 & $5.9 \%$ & 1 & $5.9 \%$ & 2 & $11.8 \%$ \\
\hline Science & 1 & $5.9 \%$ & 1 & $5.9 \%$ & 2 & $11.8 \%$ \\
\hline Total & 9 & $53.00 \%$ & 8 & $47.00 \%$ & 17 & $100.0 \%$ \\
\hline
\end{tabular}

The main focus group questions were: (1) Can you talk about your experience in teaching online during COVID-19?; (2) What type of technology you have been using since the beginning of the COVID-19 crisis?; and (3) What are the challenges you faced during teaching in online during COVID-19?

\subsection{Data Analysis}

A thematic analysis was used for data analysis of all data resources. Through thematic analysis, researchers analyzed, categorized, and reported patterns of the data collected by a qualitative approach [48]. The total data that was analyzed included 610 responses to the open-ended questions, data from the two hour focus group session, and 1750 student comments on social media. The analytical process started with analysis of the faculty members through categorizing the responses into themes related to the main dimensions generated from the research questions. The electronic form allows us to calculate the percentage of the highest type of technology the professors were using. For official document analysis, we followed [46] procedures through "skimming (superficial examination), reading (thorough examination), and interpretation" (p. 32). Thematic analysis was used for triangulation of professors' responses and focus group discussion.

The focus group session was recorded, transcribed, and analyzed using thematic analysis based on the prompts used in the discussion. The findings of the focus group session have been organized into the same themes that emerged from the faculty members' responses, and a new theme reported by the faculty members was reported, which was student attendance.

Students' comments were analyzed using thematic analysis in order to determine the reasons for their attitudes toward online courses. Different scholars suggested procedures to follow in the thematic analysis. In this study, the researchers followed the procedures suggested by [47], where they highlighted and coded repeated words, phrases, and patterns. This strategy helped to divide and assign the text under each theme. The themes that emerged from analysis of the open-ended questions were used for analyzing the data from the focus group sessions and official document analysis.

A negotiation among the researchers was conducted to arrive at an agreement on the final themes. The percentage of agreement among the professors was $89 \%$. With the final themes created, a professor in instructional technology was asked to take a small 
portion of the data and apply the codes of the themes to check the reliability and accuracy of the coding.

\subsection{Validity of Data Analysis}

Before analysis of the data from the focus group sessions, all the transcribed files were resubmitted to all the participants for member checking. We asked the participants to verify the content for accuracy, rewrite, edit, and add notes on the transcribed files, but no one added to or altered their original statements.

The researchers analyzed the data from the faculty members' responses individually, and then each one of the researchers shared the themes with each other. Negotiations on the themes among the researchers have been established to discuss the disagreement on the themes and to achieve agreement on the final themes. The percentage of agreement among them was $89 \%$. With the final themes created, a professor in instructional technology was asked to take a small portion of the data and apply the codes of the themes to check the reliability and accuracy of the coding.

\section{Findings}

Research question \#1: How has ANNU responded to the universities' closure due to the outbreak of COVID-19?

The university responded rapidly to the state of emergencies occurring due to COVID19 by forming an emergency committee to prepare for converting traditional classroom learning to online learning by establishing teaching policies during states of emergency. Official document analysis from the university revealed that the university performed different procedures to continue communicating with and supporting students and faculty members in using technology. In the following sections, the important procedures organized into themes based on priority are highlighted to support faculty members and students in the online environment. These themes played a vital role in improving the infrastructure, professional development, technical and instructional support, evaluation and assessment, quality, and accessibility.

\subsection{Faculty Members' Responses}

\subsubsection{Improving Infrastructure}

According to an official document from the eLearning center to the university administration, the eLearning center has requested the improvement of the capacity of the servers of the LMS (Moodle) to facilitate uploading of learning materials, assignments, and activities. Based on the projected number of students and their expected hits on Moodle connected to time and schedules, a team of technicians from the eLearning center and the computer center worked together to test, develop, and decide on its capacity. Meanwhile, another test was conducted regarding the internet speed, and as a result of this test, an official document was sent to the internet provider to increase the speed for the university and faculty members' lines at their homes. Hence, a team was established to keep working to monitor the LMS at all times, report any issues raised, and solve them on the spot.

\subsubsection{Professional Development and Technical Support}

Various training sessions for capacity building of faculty members were conducted on the use of online technology, including using Zoom and Big Blue Button (BBB), for synchronous (live) lectures. The training sessions were conducted over the Zoom platform. Different training guidelines for Zoom and Google Classrooms were delivered for students and professors. The eLearning team developed different microlearning videos for training on Moodle and developing and designing electronic content for distance learning. The training was based on faculty members' needs and requirements and included developing different types of guidelines such as videos, booklets, and brochures (https: / /elc.najah. edu/ar/node/12120, accessed on 20 October 2020). More than $40 \%$ of faculty members 
attended the workshops, while others had been trained on e-learning previously in the last 10 years.

Not only was technical support available, but there was also instructional support for using suitable strategies in online learning through conducting training sessions on the Zoom platform for staff from the Faculty of Science, Faculty of Engineering and Information Technology, and the Faculty of Medicine and Health Sciences. Figure 1 represents a screenshot from a training session about the strategies in online learning.

\section{قبل اللقاء Before Meeting}

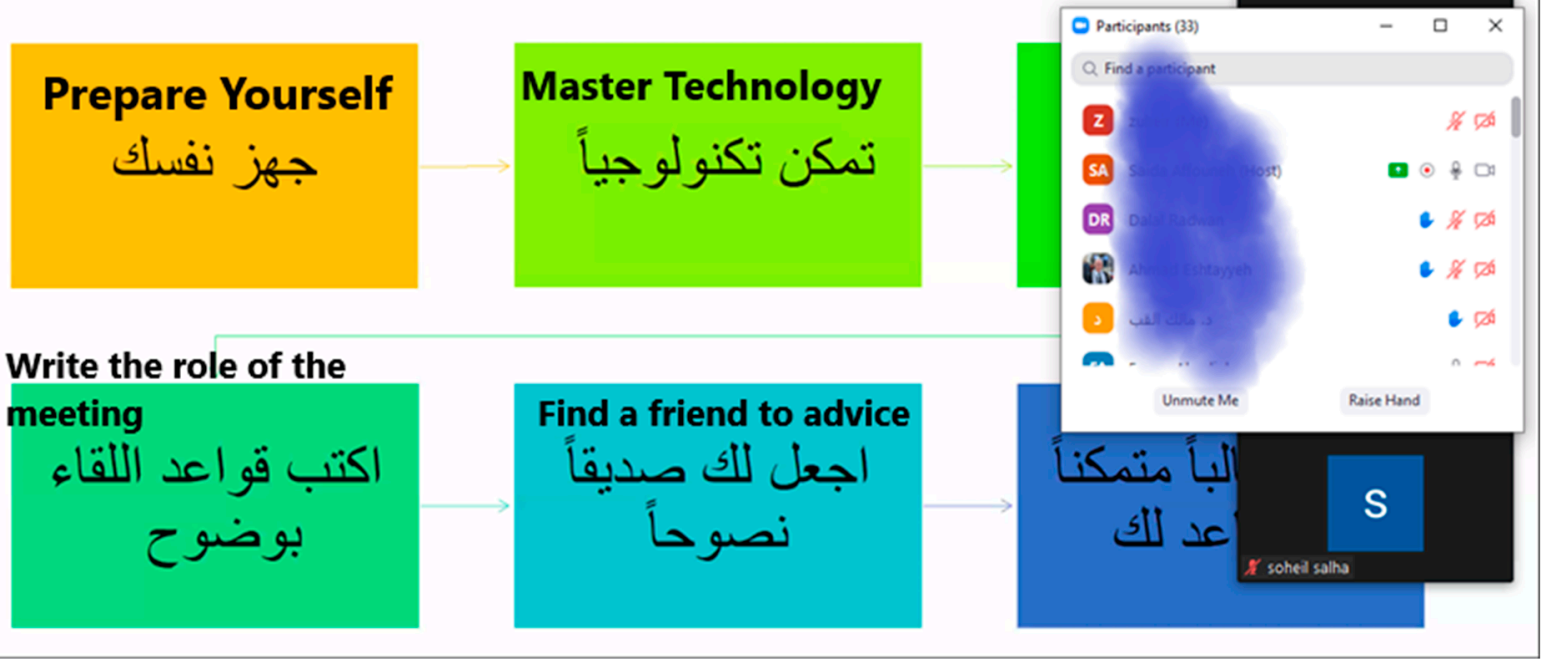

Figure 1. Screenshot from a training session covering the strategies in online learning.

\subsubsection{Evaluation and Assessment}

The focus group session main discussion was on the best methodology used for assessing and evaluating students in online learning. The participants agreed to be flexible in the evaluation process, to use a variety of tool to assess their students, to reduce pressure on students, and to take into consideration the privacy of teaching topics and students. Based on the lecturers' practices, various tools used in assessing students in online courses were reported. For example, a professor in the Faculty of Educational Sciences and Training Teachers used authentic assessments including daily/weekly tasks, projects, and reflection papers. Another professor from the Faculty of Economics used daily journals to assess his/her students. Other tools were reported by different professors such as rubrics, checklists, short quizzes, projects, presentations, and journals.

Research question \# 2: What types of emerging technologies have been used in responding to the COVID-19 outbreak at ANNU?

Emerging technological tools

The university guidelines were very flexible, which allowed professors in different faculties to use various technological tools in their online teaching. These tools are categorized into synchronous and asynchronous tools. The participants argued that the probability of using these technologies depends on the internet signal and speed (Figure 2 illustrates the percentage of using these tools). The most commonly used synchronous tools reported by participants included Zoom, BBB, and livestreaming on Facebook. Asynchronous tools included closed Facebook groups, YouTube, e-mails, and WhatsApp for uploading instructional materials and assignments, conducting discussion forums, and reminding students to complete required tasks. The majority of the participants reported the use of 
both synchronous and asynchronous tools in their online teaching in order to encourage students to interact and attend the lectures.

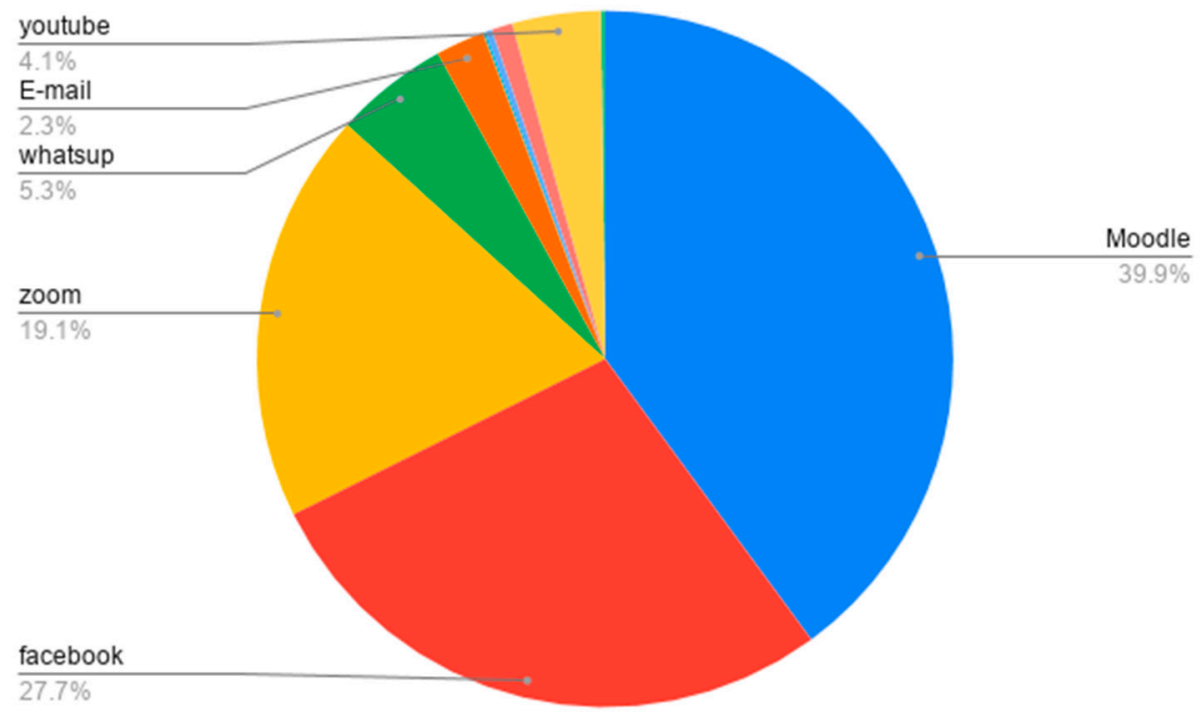

Figure 2. Percentages of use of different technological tools.

Research question \# 3: How did students respond to distance education at ANNU in Palestine during the COVID-19 crisis?

\subsection{Student Comments}

Throughout the analysis of students' comments on the university's announcement about transitioning to online teaching, the students' perspectives on the issue were divided into several groups: the first group gave its full support to the new teaching methods, the second group disagreed with the idea, and the third group suggested new ideas to adapt to the change (Figure 3). The percentage of the themes in students' comments are as follows: $60 \%$ of the students were unsatisfied with the transformation from traditional education to online teaching; $20 \%$ suggested new ideas such as canceling the semester, extending the spring semester, cancelling the summer semester, or allowing students to withdraw from the semester without any financial commitments; and $20 \%$ gave suggestions to improve the delivery of online learning. One student wrote, "Honestly, this decision [e-learning] was the best one that the university announced for us."

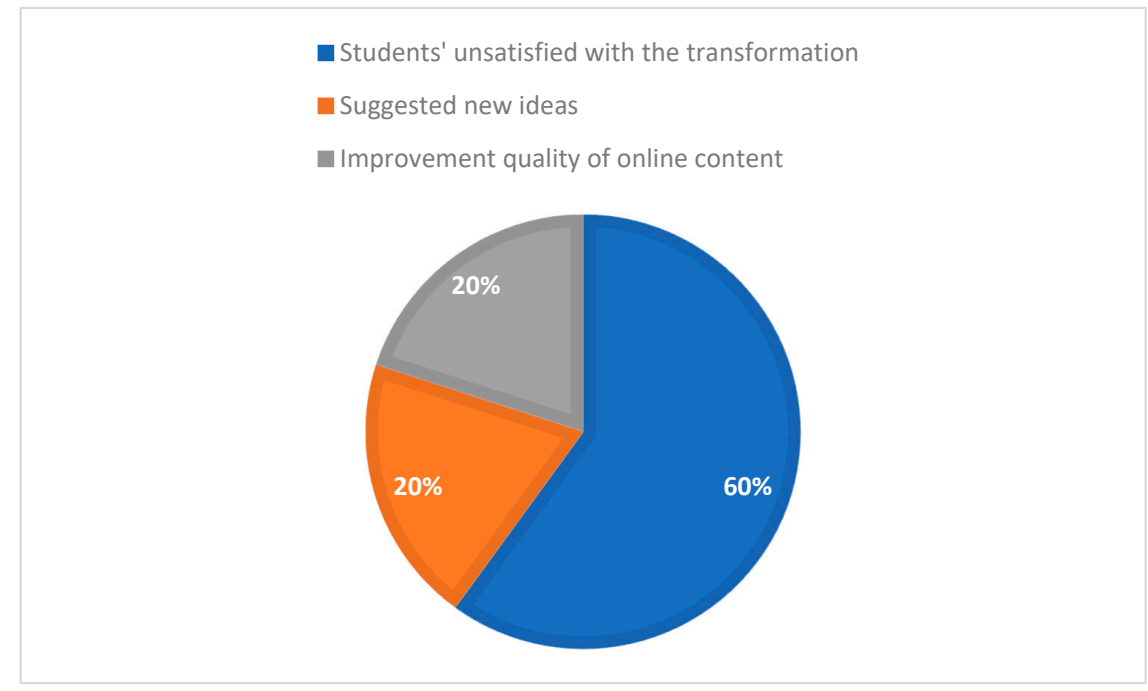

Figure 3. Percentage of the themes in students' comments. 
Students reported different reasons for their attitudes toward online education. Students expressed their worries about LMS capabilities. They also questioned their professors' abilities to work online. Some stated they were either scared about their grades decreasing or did not care at all about their education. Some comments focused on technical issues such as server shutdowns, the system not responding, content not meeting students' expectations, lack of technical support, students' lack of technological skills, and faculty members not following up on the system.

Research question \# 4: What are the challenges of distance education at ANNU from faculty members' and students' perspectives?

\subsection{Challenges}

Based on the professors' responses to the open-ended questions and students' comments on social media, as well as the findings of the focus group session, the challenges of distance education comprised four major themes: attitudes toward distance education, lack of instructional skills, technical infrastructure, and student attendance. Participants reported that they had a lot of discomfort and stress because they spent a lot of time in front of their devices to prepare for lectures to ease the transition to distance education.

\subsubsection{Faculty Members' and Students' Attitudes}

Based on the data collected and analyzed, the participants' attitudes toward distance education fell into two subthemes: positive and negative. It was immediately clear that these attitudes varied among the participants due to previous experience and the challenges they faced while using the university portal Zajel and the Moodle system.

Most of the students' comments conveyed dissatisfaction with the transition to distance education; $75 \%$ of the comments expressed a negative attitude toward distance education and expressed concern about state of the Moodle system with hundreds of students on the system. For example, one student commented that other students complained about the weak internet connection, while others argued that some of the students' families do not have enough devices, as their children use these devices for learning and to do their homework. One student commented, "We have only one laptop, [and] my sisters are using it to attend high school classes." Students' comments would be variant based on different factors such as the academic performance of students and cultural and environmental factors. The researchers did not investigate these issues because these comments were on social media page. The variant of students' comments could be a motive for a new study in the future.

A few faculty members $(2.5 \%$ of 620$)$ were dissatisfied with using distance education in the COVID-19 crisis because the transition occurred suddenly and without any preparation.

A few comments reflected satisfaction with the transition ( $25 \%$ of the comments stated that the continuation of their classes online could help them graduate earlier or get higher scores in the class). Some of the female students stressed that distance education could save time and money. One student commented that "Coronavirus has benefited us. It saves our money; I can help my family instead of going to the university."

Of the faculty members, $97.3 \%$ were satisfied using distance education to provide lectures and to communicate with their students. They reported that they were satisfied even when confronting some challenges or when they had to spend long hours in preparation for classes.

In addition to the positive and negative attitudes, in most of the comments, students urged the university to look for other solutions such as canceling the semester, expanding the semester, cancelling the summer semester, giving students the option to withdraw from the semester without any financial penalties, or improving the quality of services offered online. 


\subsubsection{Lack of Instructional Skills and Increased Work Burden}

Many faculty members mentioned that the challenges they faced were related to lack of instructional skills related to teaching strategies and the assessment process of students achievement in the distance education environment. Many faculty members were stressed from the increased number of working hours despite working from home. One of the professors stated, "I consider myself an expert in technology, but I do not know the best instructional strategies to teach online."

\subsubsection{Technical Infrastructure}

The participants reported that the technical infrastructure in the teaching and learning environment (home) is a prerequisite for the success or failure of distance of education. The participants identified problems with the technical infrastructure such as lack of Wi-Fi, lack of devices, and server shutdown. One female student stated, "when I started the first lecture online, the Internet was weak, [and] $10 \mathrm{~min}$ later, I was disconnected and out of the Zoom platform room." Another student said, "How can students learn from it [online education] without Internet or computer? I think universities should focus more on the infrastructure."

\subsubsection{Student Access}

All faculty members reported that student attendance in the classes varied from $55 \%$ to $65 \%$ in the first week, while it increased to $60-80 \%$ in the second week; this also depended on the programs and teachers. At week three, attendance increased to $70-90 \%$. Only a few professors from graduate studies confirmed the attendance of almost $99 \%$ of their students. However, students reported that their lack of attendance was due to the lack of devices at home or the slow internet connection, as they had many siblings that needed to work online at the same time. Nevertheless, the main issue that needed urgent intervention, and which was mentioned several times by students, was the lack of computers for a few students.

Some students criticized the quality of the content in the online environment compared with face-to-face content. This critique was supported by the participants in the focus group discussion. Hence, few professors requested information and training to design their course material to be suitable for the transition teaching paradigm. Most of the faculty members suggested using different methods for student evaluation and new teaching methods suitable for distance education. Overall, $90 \%$ of teachers were involved in the process from the first week, but many of them needed professional development in course design, authentic assessment and microlearning, and managing large classes online.

\section{Discussion}

The finding of the current study, which was conducted in Palestine with its unique case where people are living under crisis, could inspire decision makers in the MiddleEast area, especially the countries that are suffering from unstable and violent situation in addition to the COVID-19 crisis. This combination of factors, the usual daily stress in society and the additional restrictions from the pandemic, makes this case study a particularly challenging scenario to provide quality education under the current terms. The transition from classroom learning to online learning caused major shock and discomfort to all the university's stakeholders from the learning center team to the students. This temporary transition is a response to a state of emergency and will end when the lockdown is over. Hence, this state was considered as emergency remote education (ERE). During the process of planning for the transition, different challenges were faced, especially that of moving faculty members and students from their comfort zones to a new, vague area, which can be chaotic in the beginning [50-52]. The ERT has different consequences on the educational system such as enhancing technological innovations to be used in teaching [13], professional development of faculty member, and deepening the digital inequality in the developing countries $[13,24]$. The related challenges are focused on attitudes, skills, and 
technical infrastructure. To this extent, attitudes and skills are two of the main components of a competence (knowledge being the third one), which leads to approach the core of students and teachers competences. Both target user groups require a combined action to address the lack of an appropriate attitude toward the required change into virtualization. Indeed, although most of the students and teachers actually are in favor of and strongly support migration from face-to-face to virtual settings, the required personal process to change the standpoint in an effective way requires more attention to every step. Initial rejection to change can be easily overcome with extra individualized care and personalized mentoring; therefore, that every person involved grows awareness about the need for adaptation and applies the needed means to make it through.

In addition, skills about online instruction are scarce in faculty and need improvement. Even for those that have mastered technology, the required adaptation from face-to-face settings to online or blended ones needs to deal with longer hours of instruction and a longer process to achieve the related competences. University professors require a specific training program to help them transition between types of settings. That very training program is not just about the skills on technological tools but also about the approach to apply them efficiently. Further, if both challenges are tackled combined (attitudes and skills), the success rate will improve significantly, since both demand an assimilation process, different in every person, but mostly long and in need for cross-support.

The last challenge is technological infrastructure, which is always a challenge, regardeless of the pandemic, lockdown, or any other situation of stress. ICT becomes a significant pillar of education as a support to store resources, give lectures, share content, encourage contribution, and perform other actions. Without a powerful, diverse, and properly distributed technological layer, engaging teachers and students into online settings becomes unlikely. The tool must work properly and timely so that the target groups can focus on methodology and content, using that very tool as a means.

The procedures implemented at An-Najah were congruent with the findings of previous studies such as [53] who stated that capacity building is the core stage of e-learning. More than $80 \%$ of faculty members have been trained on e-learning skills during the last 10 years. Many different tools were used, and this was the same case around the world as was mentioned in Huang et al. [54]. The Chinese experience featured different challenges and moved toward different strategies. Some of them were confident, while others needed more training and support, but they were determined to try and innovate new methods with their motivations set very high according to $[17,38]$. On the other hand, students were demotivated to be part of the process. As Sturmer [44] argue, learners should be treated kindly in order to encourage their effective participation and motivate them. Students have the skills, but they are scared and worried about being involved in the process. The first week was very challenging, but gradually it became better, and the comments evolved from being worried about the infrastructure to complaining about the amount of assignments and homework. Therefore, moving from the chaotic stage to a state of sustainability took the university several weeks, which is consistent with the Bates [21] argument about the stages needed to move toward e-learning in higher education institutions. Student feedback was very important to the university planning team, who were able to improve accordingly. Students comments and feedback are good indicators to revisit the institution policy in online learning during crisis, but these comments should be investigated in depth to find the motivation of these comments which could be the individual characteristics, cultural factors, or environmental factors.

As the lockdown was starting in most countries in the world, e-learning became the only option that universities and schools could implement. The staff members adopted the strategy of dividing their day into three main sessions. The first was for preparing themselves for classes by redesigning their content to suit the new tools of delivery; however, some lecturers faced difficulties in implementing the online classes in programming courses, religion courses, and physics science courses, which was inconvenient for them as they would spend long hours preparing and adjusting to online teaching while they had 
other responsibilities (e.g., health, families, etc.). The second session entailed presenting their lectures online through livestreaming. The third session was for evaluating students' assignments and feedback on Moodle.

Student rejection of online learning is understandable, and this was found in many studies. Rejection was due to safe zones and theory of change, but the students' rejection moved through different stages, starting from rejecting the idea, then moving to questioning the assessment tools and grading systems, and this could be explained in the discussion of the theory of change.

The challenges emerged in the current study are expected since the transition to emergency online learning happened suddenly without any preparation for the emergency in terms of designing suitable content for the new normal ERT, adapting new evaluation methods to the ERT environment, and the change of the learning environments for schools and faculty which is in most cases is not suitable for online learning. The challenges of ERT are duplicated due to the changes in the social life and distancing orders where students and faculty members cannot get technical support, as well all students in public education and higher education being transferred to online learning mandatory.

\section{Limitations of the Study}

There were a few limitations to the study. First, the study was done as a response to the current situation and concentrates only at one university as a case study. Second, the researchers collected only data based on self-report methods. As for further studies, the researchers recommend conducting a comparative study between international universities in order to compare, analyze, and learn from them. A follow-up investigation is needed to measure the impact on student achievements, interactions, technological competencies, and family role needs at this critical stage.

\section{Conclusions}

Teaching in an online environment in normal contexts is completely different from teaching remotely in emergency situations and situations of crises, especially when the transition comes suddenly. To mitigate that impact, a collaborative community of learners was created that included teachers, students, and the university management team in order to develop the best practices to ease the teaching experience in the online environment. Therefore, there was a rapid change and move toward flexibility of university regulations and rules in order to adapt to the new situation. A new model of risk management was initiated and documented. The findings of the study provide new directions for future research which is related to students' comments to investigate the motivation of these comments, which can be qualitative, quantitative, or mixed methods. Those findings help defining a decisive shift in the university strategy to address the educational setting satisfactory. Namely, students and faculty require to work further on a positive attitude toward the migration. They would benefit from a personalized mentoring support to help them positively face the paradigm shift. Since this new angle is hard to achieve, a coordinated process must be in place. Further, professors should be required to improve their ICT skills and adapt them to online learning settings. It is not just to know how to use a tool but how to integrate it successfully according to the educational methodology. Once more, faculty should welcome a training program to support competence achievement and skill development, both required to face the virtualization process efficiently. Both challenges, attitude and skills, might be combined to cross-support one another, since both require a long process to shift the personal view and complement the current abilities. Last, technological infrastructure is the continuous challenge that becomes more crucial when a setting, online learning and remote education, in this case, makes intensive use of the related resources. A comprehensive action plan that addresses these three challenges (attitude, skills, and ICT) will become decisive in any university forced or willing to migrate from face-to-face to online or blended settings. 
Author Contributions: Conceptualization, S.A., Z.N.K., D.B., and S.S.; methodology, S.A., Z.N.K., D.B., and S.S.; validation, S.A.; Z.N.K.; and S.S.; formal analysis, S.S.; investigation, Z.N.K.; resources, S.A.; data curation, S.A.; writing —original draft preparation, S.A. and Z.N.K.; writing-review and editing, D.B.; visualization, S.S. and Z.N.K.; supervision, D.B.; project administration, S.A. All authors have read and agreed to the published version of the manuscript.

Funding: No external funding received.

Institutional Review Board Statement: Not applicable.

Informed Consent Statement: Informed consent was obtained from all subjects involved in the study.

Data Availability Statement: The data presented in this study are available on request from the corresponding author. The data are not publicly available due to the privacy of the participants since we informed them that data will not be published to public.

Conflicts of Interest: The authors declare no conflict of interest.

\section{References}

1. OHCHR. (International Covenant on Economic, Social and Cultural Rights. 1966/2015. Available online: http://www.ohchr.org/ EN/ProfessionalInterest/Pages/CESCR.aspx (accessed on 15 August 2020).

2. Yue, X.; Shao, X.; Rita, Y.M.; Li, M.; Crabbe, J.C.; Mi, L.; Hu, S.; Baker, J.S.; Liang, G. Risk management analysis for novel coronavirus in Wuhan, China. J. Risk Financ. Manag. 2020, 13, 22. [CrossRef]

3. World Health Organization. (COVID-19) Situation Dashboard-ArcGIS Experience Builder. Available online: https:/ / experience. arcgis.com/experience/685d0ace521648f8a5beeee1b9125cd (accessed on 26 March 2020).

4. Wang, C.; Cheng, Z.; Yue, X.G.; McAleer, M. Risk Management of COVID-19 by Universities in China. J. Risk Financ. Manag. 2020, 13, 36. [CrossRef]

5. Khlaif, Z.N.; Salha, S. The unanticipated educational challenges of developing countries in COVID-19 crisis: A brief report. Interdiscip. J. Virtual Learn. Med. Sci. 2020, 11, 130-134.

6. Moradi Sheykhjan, T. Mental Health and Academic Achievement among M. Ed. Students in Kerala. Online Submiss. 2017, 2, 115-123.

7. Incheon Declaration-Education 2030: Towards inclusive and equitable quality education and lifelong learning for all. In Proceedings of the World Education Forum, Incheon, Korea, 18-22 May 2015; pp. 19-22.

8. Affouneh, S. Education under Occupation: Listening to Girls Stories; Palestinian Women's Center for Research and Documentation, West Bank; UNESCO: Paris, France, 2008.

9. Shraim, K.; Khlaif, Z. An e-learning approach to secondary education in Palestine: Opportunities and challenges. Inf. Technol. Dev. 2010, 16, 159-173. [CrossRef]

10. Khlaif, Z.; Gok, F.; Kouraïchi, B. How teachers in middle schools design technology integration activities. Teach. Teach. Educ. 2019, 78, 141-150. [CrossRef]

11. Lubbe, S.; Singh, S. From conception to demise: Implications for users of information systems in changing a local parastatal educational institution in KwaZulu-Natal, South Africa. In Handbook of Research on Strategies for Local E-Government Adoption and Implementation: Comparative Studies; IGI Global: Hershey, PA, USA, 2009; pp. 832-862.

12. UNESCO. COVID-19 Education Response. 2020. Available online: https://en.unesco.org/covid19/educationresponse/ globalcoalition (accessed on 20 August 2020).

13. Khlaif, Z.N.; Salha, S.; Affouneh, S.; Rashed, H.; ElKimishy, L.A. The Covid-19 epidemic: Teachers' responses to school closure in developing countries. Technol. Pedagog. Educ. 2021, 30, 1-15.

14. Ministry of Education (Palestine). Teaching and Learning in Emergency Remote Environment Instruction. The Ministry of Education, Palestine. Available online: http:/ / www.moehe.gov.ps/eschool (accessed on 15 March 2020).

15. Affouneh, S.; Salha, S.; Khlaif, Z.N. Designing Quality E-Learning Environments for Emergency Remote Teaching in Coronavirus Crisis. Med. Sci. 2020, 11, 1-3.

16. Hussein, E.; Daoud, S.; Alrabaiah, H.; Badawi, R. Exploring undergraduate students' attitudes towards emergency online learning during COVID-19: A case from the UAE. Child. Youth Serv. Rev. 2020, 119, 105699. [CrossRef]

17. Jeffery, K.A.; Bauer, C.F. Students' responses to emergency remote online teaching reveal critical factors for all teaching. J. Chem. Educ. 2020, 97, 2472-2485. [CrossRef]

18. Toquero, C.M. Challenges and Opportunities for Higher Education Amid the COVID-19 Pandemic: The Philippine Context. Pedagog. Res. 2020, 5. [CrossRef]

19. Bao, W. COVID-19 and online teaching in higher education: A case study of Peking University. Hum. Behav. Emerg. Technol. 2020, 2, 113-115. [CrossRef]

20. Rapanta, C.; Botturi, L.; Goodyear, P.; Guàrdia, L.; Koole, M. Online university teaching during and after the Covid-19 crisis: Refocusing teacher presence and learning activity. Postdigit. Sci. Educ. 2020, 2, 923-945. [CrossRef]

21. Bates, T. Strategic Planning for E-Learning in a Polytechnic; Tony Bates Associates, Ltd.: Vancouver, BC, Canada, 2007. [CrossRef] 
22. Samigulina, G.; Samigulina, Z. Intelligent system of distance education of engineers, based on modern innovative technologies. Procedia Soc. Behav. Sci. 2016, 228, 229-236. [CrossRef]

23. Diniz, K.K.; Pagano, A.S.; Fernandes, A.P.; Reis, I.A.; Pinheiro Júnior, L.G.; Torres, H.D. Knowledge of professional healthcare providers about sickle cell disease: Impact of a distance education course. Hematol. Transfus. Cell Ther. 2019, 41, 62-68. [CrossRef]

24. Faisal, P.; Kisman, Z. Information and communication technology utilization effectiveness in distance education systems. Int. J. Eng. Bus. Manag. 2020, 12, 1-9. [CrossRef]

25. Allen, I.E.; Seaman, J. Online Report Card: Tracking Online Education in the United States; Babson Survey Research Group and Quahog Research Group: Babson Park, MA, USA, 2016.

26. Chesser, S.; Murrah, W.; Forbes, S.A. Impact of personality on choice of instructional delivery and students' performance. Am. J. Distance Educ. 2020, 34, 211-223. [CrossRef]

27. Andrade, M.S. Distance Learning Disruptions: Implications for Practice and Policy. In Proceedings of the EAIR 37th Annual Forum, Krems, Austria, 30 August-2 September 2015.

28. Aldiab, A.; Chowdhury, H.; Kootsookos, A.; Alam, F. Prospect of eLearning in higher education sectors of Saudi Arabia: A review. Energy Procedia 2017, 110, 574-580. [CrossRef]

29. Smith, G.D.; Ng, F.; Li, W.H. CCOVID-19: Emerging compassion, courage and resilience in the face of misinformation and adversity. J. Clin. Nurs. 2020, 29, 1425. [CrossRef] [PubMed]

30. Darling-Hammond, L. Learning in the Time of COVID-19. Forbes 2020. Available online: https://www.forbes.com/sites/ lindadarlinghammond/2020/03/19/learning-in-the-time-of-covid-19/\#d926b177203b (accessed on 25 March 2020).

31. Traxler, J.; Khaif, Z.; Nevill, A.; Affouneh, S.; Salha, S.; Zuhd, A.; Trayek, F. Living under occupation: Palestinian teachers' experiences and their digital responses. Res. Learn. Technol. 2019, 27. [CrossRef]

32. Seeger, M. Chaos and crisis: Propositions for a general theory of crisis communication. Public Relat. Rev. 2002, 28 , 329-337. [CrossRef]

33. Zhao, L. Mobilization and irregularity: Volatile growth of educational expenditure in China. In The Palgrave Handbook of Local Governance in Contemporary China; Palgrave Macmillan: Singapore, 2019; pp. 541-560.

34. Rhema, A.; Miliszewska, I. The potential of e-learning in assisting post-crisis countries in re-building their higher education systems: The case of Libya. Issues Inf. Sci. Inf. Technol. 2012, 9, 149-160. [CrossRef]

35. Pergel, R.; Psychogios, G. Making sense of crisis: Cognitive barriers of learning in critical situations. Manag. Dyn. Knowl. Econ. 2013, 1, 179-205.

36. Popovici, A.; Mironov, C. Students' perception on using eLearning technologies. Procedia Soc. Behav. Sci. 2015, 180, 1514-1519. [CrossRef]

37. Deverell, E.; Olsson, E. Learning from crisis: A framework of management, learning and implementation in response to crises. J. Homel. Secur. Emerg. Manag. 2019, 6. [CrossRef]

38. Khlaif, Z.N.; Salha, S.; Fareed, S.; Rashed, H. The hidden shadow of the coronavirus on education in developing countries. Online Learn. 2021, 25, 269-285. [CrossRef]

39. Messaoudi, T.; Bodin, F.; Diaz, J.H.; Ichihara, S.; Fikry, T.; Lacreuse, I.; Liverneaux, P.; Facca, S. Evaluation of a new eLearning platform for distance teaching of microsurgery. Chir. Main 2015, 34, 109-112. [CrossRef]

40. Caliskan, S.; Tugun, V.; Uzunboylu, H. University Students' Readiness for eLearning. Revista de la Facultad de Educación de Albacete. 2017, p. 32. Available online: http:/ / www.revista.uclm.es/index.php/ensayos (accessed on 15 August 2020).

41. Li, F.; Wang, L. An empirical study on distance education and job match. Sustainability 2020, 12, 619. [CrossRef]

42. Rudd, K.E.; Puttkammer, N.; Antilla, J.; Richards, J.; Heffron, M.; Tolentino, H.; Jacobs, D.J.; KatjiuanJo, P.; Prybylski, D.; Shepard, M.; et al. Building workforce capacity for effective use of health information systems: Evaluation of a blended eLearning course in Namibia and Tanzania. Int. J. Med. Inform. 2019, 131. [CrossRef]

43. Jowsey, T.; Foster, G.; Loelu, P.; Jacobs, S. Blended learning via distance in pre-registration nursing education: A scoping review. Nurse Educ. Pract. 2020. [CrossRef]

44. Stürmer, S.; Ihme, T.A.; Fisseler, B.; Sonnenberg, K.; Barbarino, M.L. Promises of structured relationship building for higher distance education: Evaluating the effects of a virtual fast-friendship procedure. Comput. Educ. 2020, 124, 51-61. [CrossRef]

45. Merriam, S.B. Introduction to qualitative research. Qual. Res. Pract. Ex. Discuss. Anal. 2002, 1, 1-17.

46. Thorndike, R.M.; Thorndike-Christ, T. Measurement and Evaluation in Psychology and Education, 8th ed.; Pearson: Boston, MA, USA, 2010.

47. Fink, A. How to Conduct Surveys: A Step-by-Step Guide; Sage Publications: Thousand Oaks, CA, USA, 2013.

48. Harlacher, J. An Educator's Guide to Questionnaire Development; Regional Educational Laboratory Central: Washington, DC, USA, 2016; p. 108.

49. Bowen, G.A. Document analysis as a qualitative research method. Qual. Res. J. 2009, 9, 27. [CrossRef]

50. Khlaif, Z.N.; Salha, S.; Kouraichi, B. Emergency remote learning during COVID-19 crisis: Students' engagement. Educ. Inf. Technol. 2021, 1-23. [CrossRef]

51. Marshall, C.; Rossman, G.B. Designing Qualitative Research; Sage: Thousand Oaks, CA, USA, 2011.

52. Affouneh, S.J.; Raba, A.A.A. An emerging model of e-learning in Palestine: The case of An-Najah National University. Creat. Educ. 2017, 8, 189-201. [CrossRef] 
53. Rosenberg, M. The Handbook of e Learning Strategy; Brandon, B., Ed.; The eLearning Guild: Santa Rosa, CA, USA, 2007.

54. Huang, R.H.; Liu, D.J.; Tlili, A.; Yang, J.F.; Wang, H.H. Handbook on Facilitating Flexible Learning During Educational Disruption: The Chinese Experience in Maintaining Undisrupted Learning in COVID-19 Outbreak; Smart Learning Institute of Beijing Normal University: Beijing, China, 2020. 